\title{
Published models and local data can bridge the gap between reference values of lung function for children and adults
}

\author{
K. Nysom*, C.S. Ulrik**, B. Hesse**, A. Dirksen+
}

Published models and local data can bridge the gap between reference values of lung function for children and adults. K. Nysom, C.S. Ulrik, B. Hesse, A. Dirksen. @ERS Journals Ltd 1997.

ABSTRACT: The aim of this study was to create reference equations for pulmonary function tests (PFTs) that span the age range from childhood to young adulthood.

PFT results (forced vital capacity (FVC), forced expiratory volume in one second (FEV1), ratio of FEV1 to FVC (FEV1/FVC), total lung capacity (TLC), transfer factor) of 348 healthy 13-24 yr old Caucasian never-smokers from a local population study were compared with 13 selected sets of published reference equations.

Predicted and observed PFT results differed significantly for 63 of 92 reference equations tested, and most equations accounted poorly for the increase in PFT variables which takes place during adolescence. We selected the equations with the best fit and adjusted their parameters, so that the level and variance of predicted values agreed with the local data. For subjects older than $18 \mathrm{yrs}$, we selected the European Community for Steel and Coal (ECSC) equations. For subjects younger than 18 yrs, we chose European summary equations for FVC, FEV1, and FEV1/FVC, and recent British equations for TLC and transfer factor.

The customized reference equations are the best available (maximum likelihood) for analysing PFTs of patients tested in our laboratory. Our approach can be used whenever generally accepted reference equations are lacking and a local sample of normal subjects is available.

Eur Respir J 1997; 10: 1591-1598.
*Section of Paediatrics, The Juliane Marie Centre for Children, Women, and Reproduction, and $* *$ Dept of Clinical Physiology and Nuclear Medicine, The National University Hospital, Rigshospitalet, Copenhagen, Denmark. +Dept of Pulmonary Medicine P, Bispebjerg Hospital, Copenhagen, Denmark.

Correspondence: K. Nysom

Section 4074

Rigshospitalet

9 Blegdamsvej

DK-2100 Copenhagen $\varnothing$

Denmark

Keywords: Adolescence, adult, child, reference values, respiratory function tests

Received: March 61996

Accepted after revision April 121997

The study has received financial support from the National Union for the Fight against Lung Diseases, the Torkil Steenbeck Foundation, the Ville Heise Foundation, and the Rosalie Petersen Foundation.
Reference values for pulmonary function test (PFT) results are often used for screening groups of patients for pulmonary disease, and for following individual patients over time. Usually, paediatric reference values are used for patients younger than 18 yrs, and adult reference values for those older than 18 yrs. Many sets of reference values have been published for children [1] or adults, as well as summary equations for children $[2,3]$ or adults [4] based on several data sets. However, predictions from paediatric and adult equations generally do not agree at 18 yrs of age, resulting in artificial changes in relative PFT values for a person passing his or her 18th birthday. Continuous reference values for children and adults are scarce, have only been published for spirometric variables, and lack residual standard deviation (RSD) values needed for calculating standardized residuals [5].

Ideally, reference equations should model the relationship between lung function measurements and factors such as sex, age and height. The equations can be modified indefinitely, but very large populations of normal subjects are needed to document the adequacy of adding any new factor [3]. In reference equations expressing common biological relations, e.g. the relation- ship of lung volumes to height and gender, the parameters of the equations may still vary between populations. Such parameters can be examined by smaller studies of normal subjects, as recommended by the American Thoracic Society (ATS) and the European Respiratory Society (ERS) [6, 7], and, if necessary, the parameters can be customized to local conditions.

The aim of this study was to bridge the gap between childhood and adulthood reference values by combining a model created for children with one designed for adults. Data from a local sample of healthy 13-24 yr olds were used to screen previously published reference equations and select the models for children and adults with the best fit. The two sets of models were then customized for use in our patients.

\section{Materials and methods}

\section{Local sample of normal subjects}

All subjects included in this analysis took part in a prospective population study of asthma, allergy and bronchial hyperresponsiveness initiated in 1986, described 
in detail by BACKER et al. [8]. In brief, a random sample of 983 children and adolescents born in the first week of each month from 1969 to 1979 , living in the area surrounding the National University Hospital Rigshospitalet in Copenhagen was drawn from the civil registration list. All subjects were Caucasians. The sample was invited by letter to a second examination in 1992 and a total of 662 (67\% of those invited) participated. Analyses of the participants and the whole sample did not reveal any signs of nonresponder bias [9-11]. All data for the present analyses were taken from the second examination. We excluded 260 ever-smokers, 52 never-smoking subjects that reported present or past symptoms indicating a diagnosis of asthma or other respiratory illness [9], one subject with Turner's syndrome, and one with Down's syndrome. We included data from 348 normal subjects (167 females). All participants and the parents of minors gave written informed consent. The study was in accordance with the Helsinki II declaration and was approved by the Medical Ethics Committee of Copenhagen, Denmark.

Participants were 13.1 to 23.8 yrs old. They were significantly taller than national reference data ([12], with modifications) from 1971-1972 (+0.47 standardized residual, 95\% confidence interval 0.36-0.57). Height-standardized residuals were not significantly related to age $(p=0.37$ for females, 0.92 for males), gender $(p=0.85)$, or age and gender combined $(\mathrm{p}=0.47$ for age, 0.88 for gender) in simple and multiple linear regression models. The mean height of participants older than $18 \mathrm{yrs}$ was $182.1 \mathrm{~cm}$ in males and $168.9 \mathrm{~cm}$ in females.

\section{Pulmonary function tests}

The forced expiratory volume in one second (FEV1) and the forced vital capacity (FVC) were measured with a pneumotachograph (Jaeger ${ }^{\circledR}$, Würzburg, Germany). Each measurement consisted of at least three maximal expiratory manoeuvres from total lung capacity (TLC) to residual volume with a variation of less than $5 \%$ in FVC and FEV1 between the two best manoeuvres. The highest FEV1 and FVC values were used, irrespective of the manoeuvre in which they occurred. The ratio of FEV1 to FVC (FEV1/FVC) was calculated and expressed as a percentage. The TLC was measured by the helium dilution technique (Jaeger $®$ ) and the transfer factor for carbon monoxide $(T \mathrm{~L}, \mathrm{CO})$ was measured with the single breath technique according to the recommendations given by the ATS [13]. The equipment detected carbon monoxide with an infra-red spectrophotometer (Jaeger®) and helium with a thermal conductivity method; average values of duplicate measurements were analysed. All values were corrected to body temperature and ambient pressure, and saturated with water vapour (BTPS). The equipment was calibrated at least once a day according to the guidelines of the manufacturer. This included volume calibration of the pneumotachograph with a manual calibration pump and an automated calibration sequence of the gas analyser.

\section{Reference equations}

Published reference equations for children were screened, and models were selected for further analysis either because they were recent and based on large data sets [3, 14-18], were widely used in Denmark [2] or elsewhere [2, 19-25], were based on Scandinavians [26], or had been recommended by the ATS and the ERS [6, 27]. Only the European Community for Steel and Coal (ECSC) reference values [4] were considered for adults, because they are the de facto standard in Denmark and most of Europe.

\section{Data analysis}

The standardized residual $\mathrm{Z}$ is defined as:

$$
\mathrm{Z}=(\mathrm{Y}-\mathrm{X}) / \mathrm{RSD}
$$

where $\mathrm{Y}=$ observed measure, $\mathrm{X}=$ predicted measure from the literature, and $\mathrm{RSD}=$ residual standard deviation from the literature.

If in a sample from the population of interest, mean $\mathrm{Z}=\mathrm{a}(\neq 0)$ and standard deviation $(\mathrm{SD})$ of $\mathrm{Z}=\mathrm{b}(\neq 1)$, a new standardized residual, $Z^{*}$, with mean 0 and SD 1 can be defined by setting:

$$
\begin{gathered}
\mathrm{X}^{*}=\mathrm{X}+\mathrm{a} \cdot \mathrm{RSD} \\
\mathrm{RSD}^{*}=\mathrm{b} \cdot \mathrm{RSD}
\end{gathered}
$$

Then the desired properties are given by:

$$
\mathrm{Z}^{*}=\left(\mathrm{Y}-\mathrm{X}^{*}\right) / \mathrm{RSD}^{*}
$$

For selecting and adjusting published reference values, the local sample of normal subjects was divided into two groups: a group of 176 adolescents $<18$ yrs of age, and a group of 172 young adults $>18$ yrs of age. Standardized residuals were calculated for the adolescents from each reference equation, except the ECSC equations, from which standardized residuals were calculated for the young adults. A good reference model adequately accounts for the change of lung function with age, so that standardized residuals of a sample of normal subjects are unrelated to age. Therefore, the relationship between standardized residuals of the adolescents and age was tested for each equation in regression models with standardized residuals as the dependent and age as the independent variable (tables 1 and 2). Predictive equations with the weakest relation of standardized residuals to age were preferred. Similarly, equations with the weakest relation of standardized residuals to height, and equations that also considered puberty or age in the predictions were preferred. To ensure that standardized residuals and height or age were not related in a nonlinear (e.g. U-shaped) fashion, plots of the data were also examined. As recommended by the ATS [7], equations for males and females were preferably chosen from the same population source.

The selected reference equations for adolescents and the ECSC equations for adults were then adjusted for optimal fit (maximum likelihood) with the local data as outlined in the equations above. The Appendix includes a calculated example of adjustments. To control the fit of the adjusted equations for extremes of height or age, new standardized residuals $\left(Z^{*}\right)$ were calculated and plotted against height and age [3].

Probabilities below 0.05 were considered statistically significant, and data were analysed using the Statistical Analysis System (SAS®) computer software package (SAS Institute, Cary, NC, USA). 
Table 1. - Pulmonary function of Danish adolescents and young adults. Mean standardized residuals and regression coefficients of standardized residuals on age (age coefficient)

\begin{tabular}{|c|c|c|c|c|c|c|c|c|c|}
\hline \multirow{3}{*}{$\frac{\text { Index }}{\text { FVC }}$} & \multicolumn{5}{|c|}{$\begin{array}{c}\text { Males } 13-18 \text { yrs of age } \\
(n=92)\end{array}$} & \multicolumn{4}{|c|}{$\begin{array}{c}\text { Females } \begin{array}{c}13-18 \text { yrs of age } \\
(\mathrm{n}=84)\end{array}\end{array}$} \\
\hline & [Ref.] & \multicolumn{2}{|c|}{ Mean (SD) } & \multicolumn{2}{|c|}{ Age coefficient $(95 \% \mathrm{CI})$} & \multicolumn{2}{|c|}{ Mean (SD) } & \multicolumn{2}{|c|}{ Age coefficient $(95 \% \mathrm{CI}$} \\
\hline & {$[3]$} & $-0.58 *$ & $(1.24 *)$ & 0.07 & $(-0.12-0.27)$ & $-0.26^{*}$ & $(1.00)$ & -0.16 & $(-0.32-0.01)$ \\
\hline FVC & [14] & $-0.26^{*}$ & $(1.00)$ & 0.26 & $(0.11-0.41)$ & $0.30^{*}$ & $(0.80 *)$ & 0.06 & $(-0.08-0.19)$ \\
\hline FVC & {$[2]$} & $0.35^{*}$ & (1.11) & 0.32 & $(0.16-0.48)$ & 0.14 & $(0.85 *)$ & 0.04 & $(-0.10-0.18)$ \\
\hline $\mathrm{FVC}$ & {$[20]$} & -0.10 & $(1.84 *)$ & 0.47 & $(0.19-0.75)$ & $0.38 *$ & $(1.01)$ & 0.04 & $(-0.14-0.21)$ \\
\hline $\mathrm{FVC}^{\dagger}$ & [26] & -0.10 & $(1.24 *)$ & 0.36 & $(0.17-0.54)$ & -0.14 & $\left(0.85^{*}\right)$ & 0.03 & $(-0.11-0.17)$ \\
\hline FVC & [25] & -0.01 & $(1.20 *)$ & 0.35 & $(0.17-0.52)$ & $0.51 *$ & (1.10) & 0.06 & $(-0.12-0.25)$ \\
\hline FVC & {$[18]$} & $-0.57 *$ & $(0.96)$ & 0.18 & $(0.03-0.33)$ & 0.08 & $(1.02)$ & 0.02 & $(-0.15-0.19)$ \\
\hline FVC $\ddagger$ & [16] & -0.03 & (1.11) & 0.14 & $(-0.03-0.32)$ & $0.22 *$ & $(0.89)$ & -0.12 & $(-0.27-0.03)$ \\
\hline FVC & {$[23]$} & $-0.74 *$ & $\left(2.18^{*}\right)$ & 0.38 & $(0.05-0.72)$ & $-1.22 *$ & $(1.83 *)$ & -0.01 & $(-0.32-0.30)$ \\
\hline FVC & [22] & 0.11 & $(1.25 *)$ & 0.28 & $(0.09-0.47)$ & $0.41 *$ & $(0.84 *)$ & -0.04 & $(-0.18-0.11)$ \\
\hline FVC & {$[24]$} & $-0.41 *$ & $(0.94)$ & 0.21 & $(0.07-0.35)$ & $-0.17 *$ & $(0.73 *)$ & 0.03 & $(-0.09-0.15)$ \\
\hline FEV1 & {$[3]$} & $-0.31^{*}$ & $\left(1.15^{*}\right)$ & 0.22 & $(0.05-0.40)$ & -0.05 & $(1.00)$ & -0.11 & $(-0.27-0.06)$ \\
\hline $\mathrm{FEV}_{1}$ & {$[14]$} & 0.06 & $(1.00)$ & 0.38 & $(0.25-0.52)$ & $0.52 *$ & $(0.84 *)$ & 0.09 & $(-0.05-0.23)$ \\
\hline FEV1 & [2] & -0.12 & $(1.63 *)$ & 0.62 & $(0.39-0.84)$ & $-0.36 *$ & $(1.25 *)$ & 0.10 & $(-0.11-0.31)$ \\
\hline FEV1 & [20] & $0.43 *$ & $\left(1.56^{*}\right)$ & 0.58 & $(0.36-0.80)$ & $0.86^{*}$ & $(0.94)$ & 0.08 & $(-0.08-0.24)$ \\
\hline FEV1 & [26] & -0.20 & $(1.12)$ & 0.44 & $(0.28-0.59)$ & $-0.22 *$ & $(0.88)$ & 0.06 & $(-0.09-0.20)$ \\
\hline FEV1 & [25] & $0.38 *$ & $(1.41 *)$ & 0.54 & $(0.35-0.74)$ & $0.64 *$ & (1.11) & 0.10 & $(-0.09-0.28)$ \\
\hline $\mathrm{FEV}_{1}$ & [18] & $-0.24 *$ & $(0.95)$ & 0.36 & $(0.22-0.49)$ & $0.38^{*}$ & $(1.14 *)$ & 0.09 & $(-0.10-0.28)$ \\
\hline FEV 1 & [16] & 0.03 & (1.06) & 0.21 & $(0.04-0.37)$ & 0.17 & $(0.86 *)$ & -0.10 & $(-0.24-0.04)$ \\
\hline FEV1 & [23] & $2.49 *$ & $\left(1.48^{*}\right)$ & 0.70 & $(0.51-0.88)$ & $1.79 *$ & $(0.92)$ & 0.14 & $(-0.02-0.29)$ \\
\hline FEV1 & {$[22]$} & 0.12 & $(1.12)$ & 0.38 & $(0.22-0.55)$ & $0.52 *$ & $(0.86 *)$ & -0.02 & $(-0.17-0.13)$ \\
\hline FEV1 & [24] & $-0.32 *$ & $(0.99)$ & 0.35 & $(0.21-0.49)$ & -0.07 & $(0.74 *)$ & 0.07 & $(-0.06-0.19)$ \\
\hline FEV1/FVC & {$[3]$} & 0.08 & $(1.31 *)$ & 0.23 & $(0.02-0.43)$ & 0.21 & $(1.28 *)$ & 0.07 & $(-0.15-0.28)$ \\
\hline FEV $1 / F V C$ & {$[14]$} & $0.50 *$ & $(0.90)$ & 0.19 & $(0.06-0.33)$ & $0.32 *$ & $(0.89)$ & 0.07 & $(-0.08-0.22)$ \\
\hline TLC & [27] & $-0.96 *$ & $(1.10)$ & 0.25 & $(0.08-0.41)$ & $-0.28 *$ & $(0.68 *)$ & 0.05 & $(-0.07-0.16)$ \\
\hline TLC & [15] & $-0.51 *$ & $(0.85 *)$ & 0.18 & $(0.05-0.31)$ & 0.07 & $(0.90)$ & 0.11 & $(-0.04-0.26)$ \\
\hline TLC & [2] & 0.21 & (1.07) & 0.30 & $(0.15-0.46)$ & -0.08 & $(0.95)$ & 0.08 & $(-0.08-0.24)$ \\
\hline TLC & [20] & -0.28 & $(1.74 *)$ & 0.49 & $(0.23-0.75)$ & -0.04 & (1.10) & 0.11 & $(-0.07-0.30)$ \\
\hline TLC & [26] & -0.02 & $(1.06)$ & 0.30 & $(0.15-0.46)$ & -0.07 & $\left(0.85^{*}\right)$ & 0.07 & $(-0.08-0.21)$ \\
\hline TLC & [25] & $-0.40 *$ & $(1.23 *)$ & 0.33 & $(0.14-0.51)$ & $0.36^{*}$ & $(1.08)$ & 0.10 & $(-0.08-0.28)$ \\
\hline TLC & {$[17]$} & $-1.27 *$ & $(0.93)$ & 0.10 & $(-0.05-0.24)$ & $-0.85^{*}$ & (1.01) & -0.04 & $(-0.22-0.13)$ \\
\hline TLC & [16] & $-0.90 *$ & $(0.94)$ & 0.01 & $(-0.14-0.16)$ & $-0.80 *$ & $(0.95)$ & -0.22 & $(-0.37--0.07)$ \\
\hline TLC & [23] & $-1.88^{*}$ & $(1.89 *)$ & 0.21 & $(-0.09-0.51)$ & $-1.90 *$ & $\left(1.85^{*}\right)$ & 0.03 & $(-0.28-0.34)$ \\
\hline TLC $\S$ & [21] & $-0.78 *$ & $(0.70 *)$ & 0.14 & $(0.03-0.25)$ & $-0.60 *$ & $(0.80 *)$ & -0.02 & $(-0.17-0.13)$ \\
\hline$T \mathrm{~L}, \mathrm{CO}$ & [15] & 0.16 & $(0.81 *)$ & 0.11 & $(-0.02-0.24)$ & $1.10 *$ & $(1.22 *)$ & 0.10 & $(-0.10-0.31)$ \\
\hline$T \mathrm{~L}, \mathrm{CO}$ & [2] & $0.98 *$ & $(0.94)$ & 0.21 & $(0.07-0.36)$ & $0.26^{*}$ & $(0.80 *)$ & 0.00 & $(-0.13-0.14)$ \\
\hline$T \mathrm{~L}, \mathrm{CO}$ & [20] & $0.80 *$ & $(0.77 *)$ & 0.22 & $(0.11-0.34)$ & 0.12 & $(0.60 *)$ & 0.02 & $(-0.08-0.12)$ \\
\hline$T \mathrm{~L}, \mathrm{CO}$ & {$[25]$} & $0.47 *$ & $\left(1.16^{*}\right)$ & 0.28 & $(0.11-0.45)$ & $0.50 *$ & $(1.01)$ & 0.02 & $(-0.15-0.19)$ \\
\hline$T \mathrm{~L}, \mathrm{CO}$ & [17] & $-0.95 *$ & $(0.92)$ & 0.08 & $(-0.07-0.23)$ & $-0.69 *$ & $(0.83 *)$ & -0.10 & $(-0.24-0.04)$ \\
\hline$T \mathrm{~L}, \mathrm{CO}$ & [23] & $4.33^{*}$ & $(2.20 *)$ & 0.75 & $(0.44-1.07)$ & $2.23^{*}$ & $(1.17 *)$ & 0.10 & $(-0.10-0.29)$ \\
\hline \multirow[t]{2}{*}{$T \mathrm{~L}, \mathrm{CO}$} & [21] & $-0.85^{*}$ & $(1.32 *)$ & 0.25 & $(0.04-0.46)$ & $-1.13^{*}$ & $(0.95)$ & 0.01 & $(-0.15-0.17)$ \\
\hline & \multicolumn{5}{|c|}{$\begin{array}{c}\text { Males } 18-24 \text { yrs of age } \\
(\mathrm{n}=89)\end{array}$} & \multicolumn{4}{|c|}{$\begin{array}{l}\text { Females } \begin{array}{c}18-24 \text { yrs of age } \\
(\mathrm{n}=83)\end{array}\end{array}$} \\
\hline FVC & [4] & $0.41 *$ & $(1.09)$ & 0.12 & $(-0.02-0.26)$ & $0.46^{*}$ & $(1.21 *)$ & 0.07 & $(-0.09-0.24)$ \\
\hline FEV1 & [4] & $0.62 *$ & $(1.05)$ & 0.12 & $(-0.01-0.26)$ & $0.48^{*}$ & $(1.08)$ & 0.02 & $(-0.13-0.16)$ \\
\hline FEV1/FVC & [4] & $0.48 *$ & $(0.89)$ & -0.01 & $(-0.13-0.10)$ & $0.55 *$ & $(0.87)$ & -0.09 & $(-0.21-0.02)$ \\
\hline TLC & [4] & $-0.55^{*}$ & (1.04) & 0.13 & $(-0.01-0.26)$ & -0.07 & $(1.14 *)$ & 0.13 & $(-0.02-0.28)$ \\
\hline$T \mathrm{~L}, \mathrm{CO}$ & [4] & $0.87 *$ & $(1.35 *)$ & 0.06 & $(-0.11-0.24)$ & -0.07 & $(1.22 *)$ & 0.03 & $(-0.13-0.20)$ \\
\hline
\end{tabular}

*: mean value significantly different from 0 or standard deviation significantly different from $1(\mathrm{p}<0.05)$; ${ }^{\dagger}$ expiratory vital capacity; expiratory volume in one second; TLC: total lung capacity; TL,CO: transfer factor for carbon monoxide.

\section{Results}

Table 1 gives the PFT results of the participants, expressed as standardized residuals based on different sets of reference values. For 55 of the 82 equations considered for adolescents, the mean standardized residual differed significantly from 0 , and for young adults, 8 of 10 mean standardized residuals differed significantly from 0 . Most standardized residuals for the adolescents were significantly related to age, especially in males (table 1). None of the PFT parameters of the young adults were significantly related to age ( $\mathrm{p}$ ranging $0.07-$ 0.82 , table 1 ). No set of reference equations were optimal for all parameters in their original form. 
Table 2. - Demographic characteristics of the reference populations

\begin{tabular}{|c|c|c|c|}
\hline [Ref.] & Participants $n$ & Age yrs & Height $\mathrm{cm}$ \\
\hline [3] & $3,592 / 2,269$ & $6-21$ & $110-205 / 110-185$ \\
\hline [27] & $106 / 65$ & $5-38 / 5-25$ & $110-203 / 105-183$ \\
\hline$[14,15]$ & $445 / 327$ & $5-19$ & $108-188 / 108-178$ \\
\hline$[2]^{\dagger}$ & $\begin{array}{l}\text { Varies considerably } \\
>45,000 \text { for FVC, } \\
\text { but } 59 \text { for } T \mathrm{~L}, \mathrm{CO}[28\end{array}$ & $\begin{array}{l}\text { y: } \\
8]\end{array}$ & - \\
\hline \multirow[t]{2}{*}{ [20] } & $\begin{array}{l}86 / 87 \text { (FVC, } \\
\text { FEV1, TLC) }\end{array}$ & $6-18$ & $118-181 / 107-173$ \\
\hline & $36 / 20(T \mathrm{~L}, \mathrm{CO})$ & $5-17$ & $107-178$ \\
\hline [26] & $75 / 65$ & $7-18$ & $120-192 / 125-180$ \\
\hline [25] & $104 / 108$ & $8-16$ & 119-180/115-169 \\
\hline$[17,18]$ & $204 / 152$ & $8-28 / 12-20$ & $126-190 / 123-170$ \\
\hline [16] & 543 & $8-19$ & 120-190/120-176 \\
\hline [23] & $62 / 77$ & $4-18$ & $111-183 / 111-183$ \\
\hline \multirow[t]{2}{*}[21,22]{} & $\begin{array}{c}131 / 96 \\
(\mathrm{FVC}, \mathrm{FEV} 1)\end{array}$ & $12-25 / 11-20$ & $140-193 / 132-183$ \\
\hline & $\begin{array}{c}28 / 30 \\
\text { (TLC, TL,CO) }\end{array}$ & $9-25 / 7-20$ & $\geq 130 / \geq 127$ \\
\hline [24] & $338 / 382$ & $7-20$ & $111-200 / 111-180$ \\
\hline$[4]^{\dagger}$ & Different & $25-70$ & $155-195 / 145-180$ \\
\hline
\end{tabular}

For further analyses of adolescents, we selected the predictive equations of QUANJER et al. [3] for FVC, FEV1, and FEV1/FVC, and those of Rosenthal et al. [15] for TLC and transfer factor. Five of the 10 paediatric equations selected and eight of the 10 adult ones had a mean standardized residual significantly different from 0 (table 1). The SD of the standardized residuals was significantly different from 1 in seven of the 10 paediatric equations selected, and in six of the 10 adult ones (table 1). Tables 3 and 4 give the selected predictive equations in their original and customized versions. To illustrate the consequences of our adjustments, tables 3 and 4 include old and new predicted values for average persons, and figure 1 shows the standardized residuals of FVC in males and transfer factor in females, calculated from the original and customized equations. Plots of the new standardized residuals against height and age revealed no tendencies to extreme values in patients with extreme heights or ages, except for one outlier. The new standardized residuals were not significantly related to age or height $(\mathrm{p}=0.08-0.80)$ when considering males and females separately over the whole age range (13-24 yrs).

At age $18 \mathrm{yrs}$, predictions for subjects of average height from the original paediatric and adult equations differed on average 0.6 standardized residuals for FVC, FEV1, and FEV1/FVC and 0.7 standardized residuals

Table 3. - Original and customized equations predicting the pulmonary function of healthy young Danish males

\begin{tabular}{|c|c|c|c|c|c|c|c|}
\hline \multirow[b]{2}{*}{ [Ref.] } & \multirow[b]{2}{*}{ Original equation } & \multirow[b]{2}{*}{ RSD } & \multirow[b]{2}{*}{ Customized equation } & \multirow[b]{2}{*}{ RSD } & \multicolumn{3}{|c|}{ Calculated examples* } \\
\hline & & & & & Before & After & $\%$ change \\
\hline \multicolumn{8}{|l|}{$<18$ yrs of age } \\
\hline $\ln \mathrm{FVC}$ & $(1.3731+0.0164 \cdot \mathrm{A}) \cdot \mathrm{H}-1.2782$ & 20.1033 & $(1.3731+0.0164 \cdot \mathrm{A}) \cdot \mathrm{H}-1.3386$ & 0.1276 & 4.59 & 4.32 & -5.9 \\
\hline ln FEV1 & $(1.2669+0.0174 \cdot \mathrm{A}) \cdot \mathrm{H}-1.2933$ & 30.1097 & $(1.2669+0.0174 \cdot \mathrm{A}) \cdot \mathrm{H}-1.3271$ & 0.1257 & 3.86 & 3.73 & \\
\hline $\mathrm{FEV}_{1} / \mathrm{FVC}[3]$ & 86.21 & 5.58 & 86.68 & 7.32 & 86.21 & 86.68 & +0.5 \\
\hline TLC & if $\mathrm{H} \leq 1.625: 4.976 \cdot \mathrm{H}-3.828$ & $\operatorname{Pr} \cdot 0.12$ & $4.672 \cdot \mathrm{H}-3.594$ & $\operatorname{Pr} \cdot 0.11$ & & & \\
\hline [15] & if $\mathrm{H}>1.625: 9.586 \cdot \mathrm{H}-10.648$ & $\mathrm{P}$ & $9.000 \cdot \mathrm{H}-9.997$ & . & 5.94 & 5.57 & -6.1 \\
\hline $1 \mathrm{~L}, \mathrm{CO}$ & if $\mathrm{H}>1.625: 17.3 \cdot \mathrm{H}-19.0$ & $+0.043)$ & $0.2276 \cdot \mathrm{H}^{2}+17.2 \cdot \mathrm{H}$ & 112 & 10.93 & 11.34 & +3.7 \\
\hline \multicolumn{8}{|c|}{$\geq 18$ yrs of age } \\
\hline $\begin{array}{l}\text { FVC } \\
\text { FEV1 }\end{array}$ & $5 . .76$ & 0.61 & $5.76 \cdot \mathrm{H}-0.0$ & 0.67 & 5.50 & 5.75 & +4.5 \\
\hline $\begin{array}{l}\text { FEV1 } 14] \\
\text { FEV1/FVC [4] }\end{array}$ & $\begin{array}{l}4.30 \cdot \mathrm{H}-0.029 \cdot \mathrm{Ax}-2.4 \\
-0.18 \cdot \mathrm{Ax}+87.21\end{array}$ & $\begin{array}{l}0.51 \\
7.17\end{array}$ & $\begin{array}{l}4.30 \cdot \mathrm{H}- \\
-0.18 \cdot \mathrm{A}\end{array}$ & $\begin{array}{l}0.54 \\
6.38\end{array}$ & $\begin{array}{r}4.62 \\
82.71\end{array}$ & $\begin{array}{r}4.94 \\
86.18\end{array}$ & $\begin{array}{l}+6.9 \\
+4.2\end{array}$ \\
\hline TLC & 7.99·Н-7.08 & 0.70 & 7.99·H-7.47 & 0.73 & 7.47 & 7.08 & -5.2 \\
\hline$T \mathrm{~L}, \mathrm{CO}$ & $11.11 \cdot \mathrm{H}-0.066 \cdot \mathrm{Ax}-6.03$ & 1.41 & $11.11 \cdot \mathrm{H}-0.066 \cdot \mathrm{Ax}-4.80$ & 1.91 & 12.55 & 13.78 & +9.8 \\
\hline
\end{tabular}

*: original and customized models applied on 15 and $21 \mathrm{yr}$ old males of average height (1.730 and 1.821 m). FVC, FEV1 and TLC are predicted in $\mathrm{L}, \mathrm{FEV} 1 / \mathrm{FVC}$ in $\%$ and $\mathrm{TL}, \mathrm{CO}$ in $\mathrm{mmol} \cdot \mathrm{min}^{-1} \cdot \mathrm{kPa}^{-1}$. A: age (yrs); $\mathrm{H}$ : standing height (m); Pr: predicted value; Ax: age (yrs) but 25 if age is less than 25 [4]. For further definitions, see legend to table 1.

Table 4. - Original and customized equations predicting the pulmonary function of healthy young Danish females

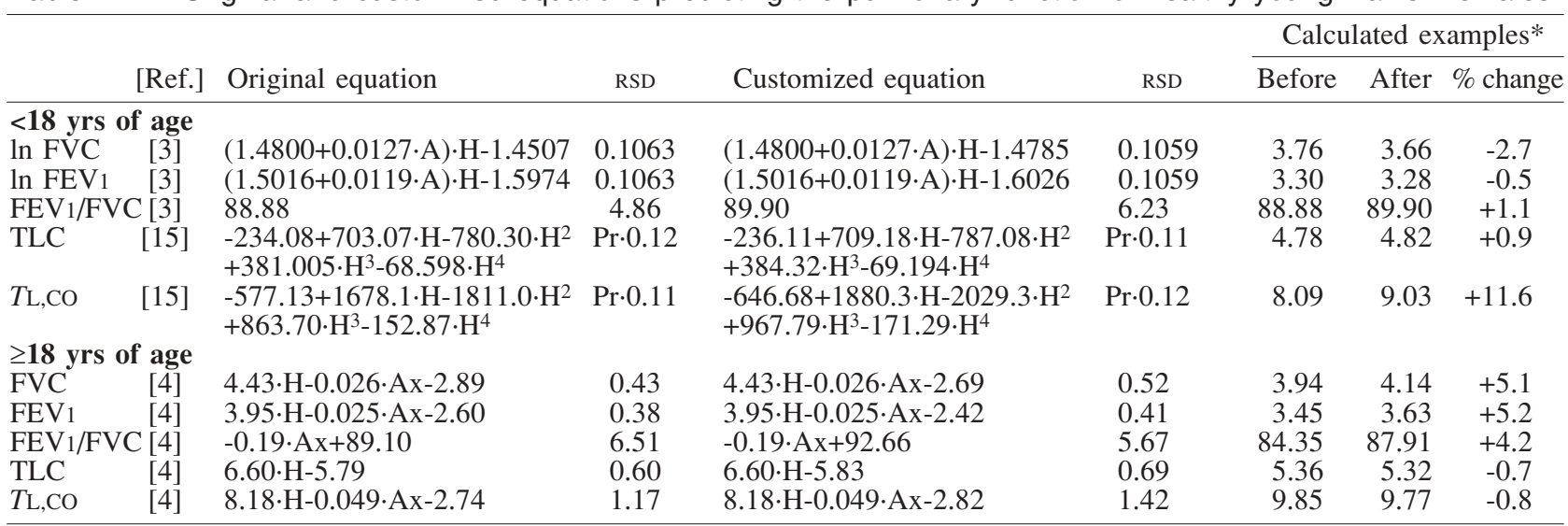

*: original and customized models applied on 15 and $21 \mathrm{yr}$ old females of average height (1.661 and 1.689 m). FVC, FEV1 and TLC are predicted in L, FEV1/FVC in $\%$ and $T \mathrm{~L}, \mathrm{CO}$ in $\mathrm{mmol} \cdot \mathrm{min}^{-1} \cdot \mathrm{kPa}^{-1}$. For further definitions, see legend to table 3. 

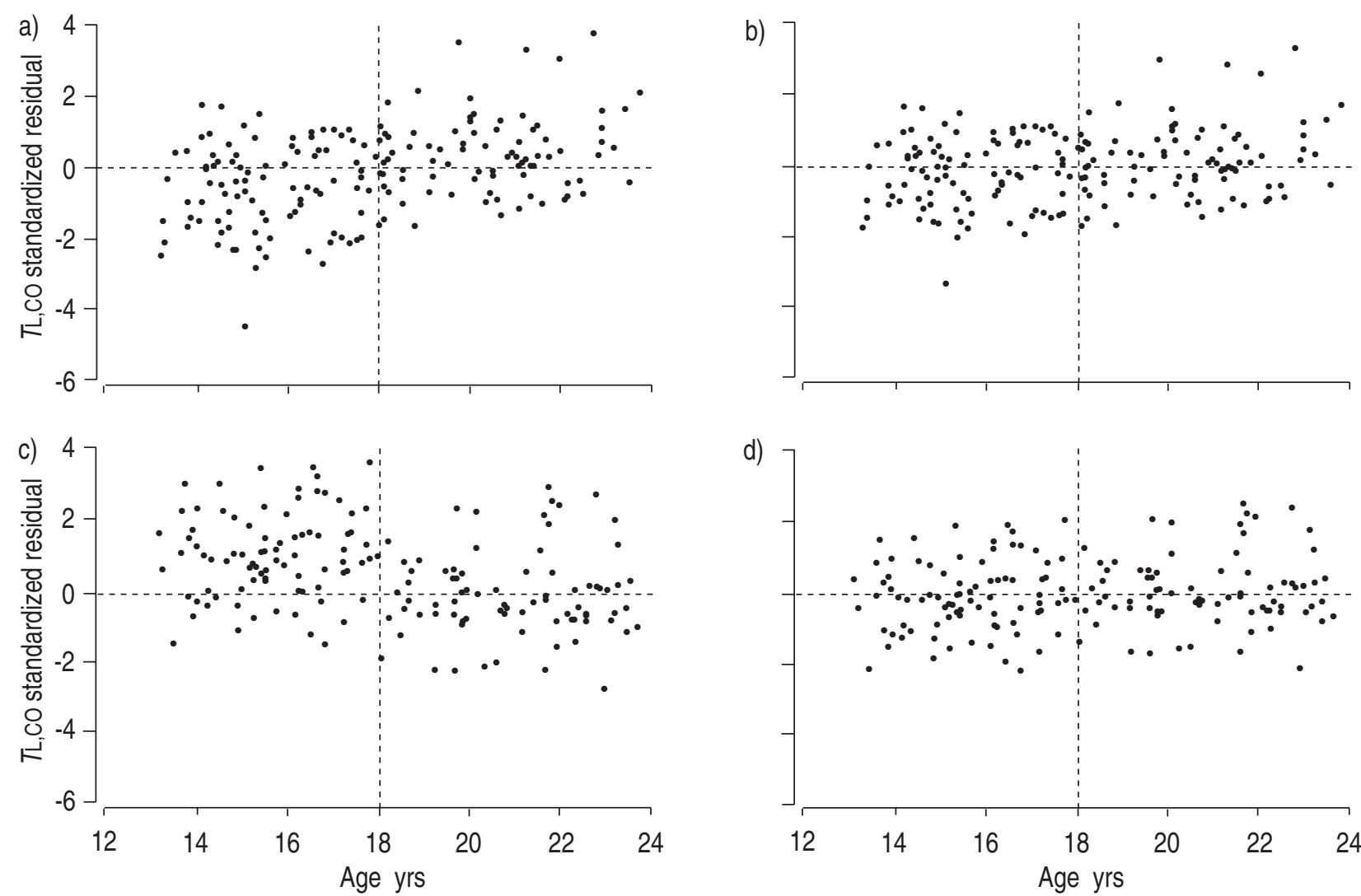

Fig. 1. - Forced vital capacity (FVC) of males and transfer factor of carbon monoxide (TL,CO) of females standardized from paediatric reference values for subjects $<18$ yrs of age and from adult reference values for those $>18 \mathrm{yrs}$. a) FVC of males, based on the original predicted values. b) FVC of males, based on the customized reference equations. c) TL,CO of females, based on original predicted values. d) TL,CO of females, based on the customized reference equations (tables 3 and 4).

for TLC and transfer factor. Predictions from the customized equations differed 0.2 standardized residuals for FVC, FEV1, and FEV1/FVC and 0.5 standardized residuals for TLC and transfer factor. Adult equations predicted higher values than the paediatric ones, except for $\mathrm{FEV} 1 / \mathrm{FVC}$.

\section{Discussion}

Reference equations are usually established to assess PFT results of other subjects, but this can also be done without using reference equations. One possibility is a case-control design [29] where each case is matched on important variables such as sex, age, and height, to one or more controls selected from the reference sample. PFT results of cases and controls can then be compared directly. This approach is conceptually simple, but less attractive for other reasons: it is quite complicated and labour-intensive in practice, the process is less transparent, and the statistical power depends on finding adequately matching controls for all cases.

Another possibility is to develop a set of new reference equations. Our sample of normal subjects was, however, small in number and narrow in age range. Furthermore we believe that models of the relationship between sex, age, height and PFT results that have been developed in studies with hundreds or thousands of participants (table 2) reflect a true biological relationship, which our limited data would not have the statistical power to describe.
Therefore, as a compromise between crude nonmodel comparisons and uncritical use of available reference equations, we decided to use our data to select the best models among published reference equations, and customize the parameters of these models to ensure an optimal fit for our sample of normal subjects. We customized all selected equations fully to maintain consistency, although some predictions (e.g. FEV1 of female adolescents and transfer factor of male adolescents) were so close to the observed values that others might have preferred to leave them unchanged.

The mean, SD and age relationship of standardized residuals varied widely in our population, depending on which reference equations were used. This could be caused by differences in study populations, equipment, technicians, procedures, or data analyses. Recently, wrong correction of pneumotachograph volume measurements to BTPS has been indicated as a major source of error [3].

Good models of the growth of pulmonary function during childhood, adolescence, and adulthood are difficult to create and should be re-evaluated when the height or age at onset of puberty of a population changes considerably. Lung volumes and height do not grow in parallel $[16,30]$, so models based on more than height are necessary. The only published continuous models of pulmonary function from childhood to old age [5] described the development of spirometric variables by a number of linear models for consecutive age intervals with intervening "breakpoints" where the linear segments joined exactly. Breakpoints occurred at different ages and the 
regression coefficients of lung function on age differed in various age intervals, for various indices of pulmonary function, and for males and females. FVC and FEV1 of males increased slowly with age until 12 yrs of age, and then increased rapidly until age 17 (FEV1) or 18 yrs (FVC), and continued to grow slowly until onset of the decline at age 26. In females, the increased growth rate occurred earlier (age 10-16 yrs) and was less pronounced than in males. After that, FEV1 continued to grow slowly until age 27 yrs, whereas FVC started to decline at age 17 yrs. For each sex and PFT variable, one regression coefficient for height or height ${ }^{2}$ fitted the full age range of 6-90 yrs. We could not include the continuous models in table 1 because they lacked RSDs, but percentage predicted values calculated for our whole cohort were positively related to height (female FEV1) or to height and age (male FVC and FEV1, data not shown).

A longitudinal study of children and adolescents found that lung volumes did not increase in females after 18 yrs of age, and increased only slightly in males [31]. Partly in contrast with the longitudinal studies, the ECSC working party assumed that lung function parameters of 18 to $25 \mathrm{yr}$ olds did not vary with age [4]. Our data on young adults could neither confirm nor reject any of these assumptions unequivocally: standardized residuals calculated from the ECSC equations were not significantly related to age (table 1) but FVC and FEV1 in males were positively related to height $(\mathrm{p}=0.01$ and 0.02). For all parameters except male FVC and FEV1, our data could not exclude that the lung function between ages 18 and 25 yrs decreases at the same rate as after the age of 25 [4]. When percentage predicted FVC and FEV1 of our young adults were calculated from the continuous reference equations [5], FVC and FEV1 in males and FEV1 in females were all positively related to height ( $\mathrm{p}=0.004,0.02$, and 0.0008 , respectively).

We used 18 yrs as the cut-off between paediatric and adult predictive equations for both pragmatic and scientific reasons. In Denmark, the ECSC reference values [4] are a de facto standard for subjects $>18$ yrs. A recent study showed that, concerning flow-volume indices, the ECSC reference values for adults were appropriate for 100 Dutch conscripts aged 18-19 yrs [32]. Finally, most reference equations for children are based on subjects with a maximal age of 16-18 yrs. Only the recent European equations [3] extend past the age of $20 \mathrm{yrs}$.

The ATS and the ERS $[6,7]$ both recommend choosing reference values for PFT results that are likely to, or have been shown to, fit local data. In the present study we could extend the recommended approach of using a local sample of 10-20 subjects for screening the available predictive equations, because we had a larger sample of normal subjects. A recent survey found that two sets of reference values for lung volumes of adults were used by approximately $85 \%$ of PFT laboratories in North America, although numerous other sets were available [33]. A similar tendency was found in the use of paediatric reference values [19]. Reference values were often chosen because they were available in the PFT equipment of the laboratories, rather than because they had been analysed and found to be the best for the local population $[19,33]$. In Denmark, most PFT laboratories use the predictive equations of Polgar and Promadhat
[2] for children, and the ECSC reference values [4] for adults. We are not aware of any data that confirm the adequacy of these choices, and none of these models fitted our participants perfectly before adjustment. The reference values of POLGAR and PROMADHAT [2] are used, although several larger, more recent, and more thoroughly analysed data sets are available [1, 3, 14-16]. The equations of Polgar and Promadhat [2] fitted our female adolescents reasonably well whereas standardized residuals for male adolescents were positively related to age (table 1). The latter is in accordance with a recent study where the equations of Polgar and Promadhat [2] were applied to a large combined European data set [3]. In that study, however, the tendency was found in both males and females. The ECSC reference values are based on large data sets, but are not ideal for all parameters [32], in part because some equations are based on smokers as well as nonsmokers [6].

Our participants were taller than the $20 \mathrm{yr}$ old national reference values. This was expected because of the secular trend in height. It is a weakness of our study that all subjects were in a $10 \mathrm{yr}$ age range. In particular, we would have liked to study children younger than 13 yrs to see if our adjusted predictive equations were also appropriate for this age group.

It should be emphasized that our customized equations will probably not fit perfectly for other laboratories, even locally, because equipment, procedures, and technicians vary. But our approach to the problem is general, can be copied, and will result in more appropriate predictive equations than simply combining the best unadjusted equations for children and adults. Our equations are good cross-sectional reference values for adolescents and young adults tested in our laboratory, because we: a) studied a population sample with a high percentage participating; b) strictly excluded from analysis all smokers and subjects with chronic diseases or known or suspected lung disease; c) had many participants in the critical age range from adolescence to young adulthood; and d) adjusted the equations for optimal fit at all ages. Longitudinal PFT data might not fit reference values based on cross-sectional data because of a potential cohort effect. One study found a cohort effect in children [34] whereas another did not [35]. In adults, reference values generated using cross-sectional methods predict a larger annual decrease in lung function than do equations calculated longitudinally [5].

We believe that the present approach to reference values is a convenient compromise between crude nonmodel comparisons and uncritical use of published reference equations, and that our approach could be useful in other fields where generally accepted reference equations are lacking.

\section{Appendix}

A calculated example of adjustments (FVC of males) is given below.

\section{Original equations (table 3)}

$<18$ yrs [3] ln $\mathrm{FVC}=(1.3731+0.0164 \cdot \mathrm{A}) \cdot \mathrm{H}-1.2782 \mathrm{RSD}=0.1033$ $\geq 18$ yrs [4] $\mathrm{FVC}=5.76 \cdot \mathrm{H}-0.026 \cdot \mathrm{Ax}-4.34 \quad \mathrm{RSD}=0.61$ 
where $\mathrm{A}=$ age (yrs), $\mathrm{H}=$ standing height $(\mathrm{m})$ and $\mathrm{Ax}=$ age (yrs), but 25 if age is less than 25 .

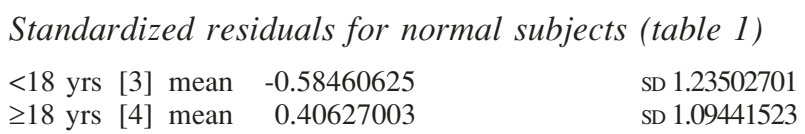

Raw adjusted equations

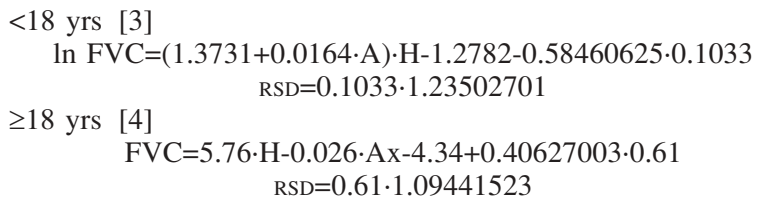

Abbreviated adjusted equations (table 3)

$<18$ yrs [3]

$\ln \mathrm{FVC}=(1.3731+0.0164 \cdot \mathrm{A}) \cdot \mathrm{H}-1.3386 \mathrm{RSD}=0.1276$

$\geq 18$ yrs [4]

$$
\mathrm{FVC}=5.76 \cdot \mathrm{H}-0.026 \cdot \mathrm{Ax}-4.09 \mathrm{RSD}=0.67
$$

For $T \mathrm{~L}, \mathrm{CO}$ of males $<18 \mathrm{yrs}$, the RSD of the original equation is related to height. Therefore the adjustment is more complicated.

Original equations. If $\mathrm{H} \leq 1.625$ :

where $\operatorname{Pr}=$ predicted value.

$$
\begin{gathered}
T \mathrm{~L}, \mathrm{CO}=7.0 \cdot \mathrm{H}-3.99 \\
\mathrm{RSD}=\operatorname{Pr} \cdot(0.08 \cdot \mathrm{H}+0.043)
\end{gathered}
$$

\section{Raw adjusted equations}

$T \mathrm{~L}, \mathrm{CO}=(7.0 \cdot \mathrm{H}-3.99)(1+0.16444416 \cdot(0.08 \cdot \mathrm{H}+0.043))$ $\operatorname{RSD}=\operatorname{Pr} \cdot(0.043+0.08 \cdot \mathrm{H}) \cdot 0.812048 /(1+0.16444416 \cdot(0.043 \pm 0.08 \cdot \mathrm{H}))$

\section{Abbreviated adjusted equations}

$$
\begin{gathered}
T \mathrm{~L}, \mathrm{CO}=0.09209 \cdot \mathrm{H}^{2}+7.0 \cdot \mathrm{H}-4.02 \\
\mathrm{RSD}=\operatorname{Pr} \cdot(2.65+4.94 \cdot \mathrm{H}) /(76.6+\mathrm{H})
\end{gathered}
$$

Acknowledgement: The authors are indebted to V. Backer for having initiated the population-based study of asthma, allergy, and bronchial hyperresponsiveness in 1986 .

\section{References}

1. Quanjer PH, Helms P, Bjure J, Gaultier C. Standardization of lung function tests in paediatrics. Eur Respir J 1989; 2 Suppl. 4: 121s-265s.

2. Polgar G, Promadhat V. Pulmonary function testing in children: techniques and standards. Philadelphia, W.B. Saunders, 1971.

3. Quanjer PH, Borsboom GJ, Brunekreef B, et al. Spirometric reference values for white European children and adolescents: Polgar revisited. Pediatr Pulmonol 1995; 19: 135-142.

4. Quanjer PH, Tammeling GJ Summary of recommendations. Standardized lung function testing. Report Working Party, European Community for Coal and Steel. Bull Eur Physiopathol Respir 1983; 19 Suppl. 5: 7-10.

5. Sherrill DL, Lebowitz MD, Knudson RJ, Burrows B Continuous longitudinal regression equations for pulmonary function measures. Eur Respir J 1992; 5: 452462.
6. Stocks J, Quanjer PH. Workshop report. Reference values for residual volume, functional residual capacity and total lung capacity. ATS workshop on lung volume measurements. Eur Respir J 1995; 8: 492-506.

7. Lung function testing: selection of reference values and interpretative strategies (see comments). American Thoracic Society. Am Rev Respir Dis 1991; 144: 1202-1218.

8. Backer V, Bach-Mortensen N, Dirksen A. Prevalence and predictors of bronchial hyperresponsiveness in children aged 7-16 years. Allergy 1989; 44: 214-219.

9. Ulrik CS. Factors associated with increased bronchial responsiveness in adolescents and young adults: the importance of adjustment for prechallenge FEV1. $J$ Allergy Clin Immunol 1996; 97: 761-767.

10. Ulrik CS. Comparison of stayers, dropouts, and newcomers in a longitudinal population study of asthma and bronchial hyperresponsiveness: introduction of bias? $J$ Asthma 1995; 32: 295-300.

11. Ulrik CS, Backer V. Increased bronchial responsiveness to exercise as a risk factor for symptomatic asthma: findings from a longitudinal population study of children and adolescents. Eur Respir J 1996; 9: 16961700 .

12. Andersen E, Andersen H, Hutchings B, et al. Heights and weights in Danish school children in 1971-1972. Ugeskr Laeger 1974; 136: 2796-2802 (in Danish).

13. Single breath carbon monoxide diffusing capacity (transfer factor). Recommendations for a standard technique. Statement of the American Thoracic Society. Am Rev Respir Dis 1987; 136: 1299-1307.

14. Rosenthal M, Bain SH, Cramer D, et al. Lung function in white children aged 4 to 19 years: I. Spirometry. Tho$\operatorname{rax} 1$ 1993; 48: 794-802.

15. Rosenthal M, Cramer D, Bain SH, Denison D, Bush A, Warner JO. Lung function in white children aged 4 to 19 years. II. Single breath analysis and plethysmography. Thorax 1993; 48: 803-808.

16. Hibbert ME, Lannigan A, Landau LI, Phelan PD. Lung function values from a longitudinal study of healthy children and adolescents Pediatr Pulmonol 1989; 7 : 101-109 (published erratum appears in Pediatr Pulmonol 1990; 8; 68).

17. Paoletti P, Viegi G, Pistelli G, et al. Reference equations for the single-breath diffusing capacity A crosssectional analysis and effect of body size and age. $\mathrm{Am}$ Rev Respir Dis 1985; 132: 806-813.

18. Paoletti P, Pistelli G, Fazzi P, et al. Reference values for vital capacity and flow-volume curves from a general population study. Bull Eur Physiopathol Respir 1986; 22: 451-459.

19. Pattishall EN. Pulmonary function testing reference values and interpretations in pediatric training programs. Pediatrics 1990; 85: 768-773.

20. Zapletal A, Samanek M, Paul T. Lung function in children and adolescents. Methods, reference values. Basel, Karger, 1987.

21. Knudson RJ, Kaltenborn WT, Knudson DE, Burrows B The single-breath carbon monoxide diffusing capacity. Reference equations derived from a healthy nonsmoking population and effects of hematocrit. Am Rev Respir Dis 1987; 135: 805-811.

22. Knudson RJ, Lebowitz MD, Holberg CJ. Burrows B. Changes in the normal maximal expiratory flow-volume curve with growth and aging. Am Rev Respir Dis 1983; 127: 725-734.

23. Weng TR, Levison H. Standards of pulmonary function in children. Am Rev Respir Dis 1969; 99: 879-894. 
24. Hsu KH, Jenkins DE, Hsi BP, et al. Ventilatory functions of normal children and young adults: MexicanAmerican, white, and black. I. Spirometry. J Pediatr 1979; 95: 14-23.

25. Cotes JE, Leathart GL, eds. Lung function: Assessment and application in medicine, 5th (revised) Edn. Oxford, Blackwell Scientific Publications, 1993.

26. Solymar L, Aronsson PH, Bake B, Bjure J. Nitrogen single breath test, flow-volume curves and spirometry in healthy children, 7-18 years of age. Eur J Respir Dis 1980; 61: 275-286.

27. Cook CD, Hamann JF. Relation of lung volumes to height in healthy persons between the ages of 5 and 38 years. J Pediatr 1961; 59: 710-714.

28. Bucci G, Cook CD, Barrie H. Studies of respiratory physiology in children. V. Total lung diffusion, diffusion capacity of pulmonary membrane and pulmonary capillary blood volume in normal subjects from 7 to 40 years of age. J Pediatr 1961; 58: 820-828.

29. Sveger T, Piitulainen E, Arborelius M Jr. Lung function in adolescents with alpha 1-antitrypsin deficiency. Acta Paediatr 1994; 83: 1170-1173.
30. Borsboom GJ, Van Pelt W, Quanjer PH. Interindividual variation in pubertal growth patterns of ventilatory function, standing height, and weight. Am J Respir Crit Care Med 1996; 153: 1182-1186.

31. Hibbert ME, Lannigan A, Raven J, Landau LI, Phelan PD. Gender differences in lung growth. Pediatr Pulmonol 1995; 19: 129-134.

32. Stevens WH, van Hartevelt JH, The PE, Smink HA, Quanjer PH. Validity of ECSC prediction equations for spirometric indices in Dutch conscripts. Eur Respir $J$ 1994; 7: 29-34.

33. Ghio AJ, Crapo RO, Elliott CG. Reference equations used to predict pulmonary function. Survey at institutions with respiratory disease training programs in the United States and Canada. Chest 1990; 97: 400-403.

34. Pattishall EN, Helms RW, Strope GL. Noncomparability of cross-sectional and longitudinal estimates of lung growth in children. Pediatr Pulmonol 1989; 7: 2228.

35. Hibbert ME, Hudson IL, Lanigan A, Landau LI, Phelan PD. Tracking of lung function in healthy children and adolescents. Pediatr Pulmonol 1990; 8: 172-177. 